\title{
The role of an alpha animal in changing environmental conditions
}

\author{
Konstanze Krueger ${ }^{\mathrm{ab}}$, Riccarda Wolter ${ }^{\mathrm{ab}^{*}}$, Norbert Pantel ${ }^{\mathrm{c}}$, Volker Stefanski ${ }^{\mathrm{d}}$, Erich Möstle \\ ${ }^{a}$ University of Regensburg Department of Biology I \\ ${ }^{\text {b} U n i v e r s i t y ~ o f ~ A p p l i e d ~ S c i e n c e s ~ N u e r t i n g e n, ~ F a c u l t y ~ A g r i c u l t u r e, ~ E c o n o m i c s ~ a n d ~ M a n a g e m e n t, ~ D e p a r t m e n t ~ E q u i n e ~ M a n a g e m e n t ~}$ \\ 'Landschaftspflegeverband Stadt Augsburg e.V., Dr.-Ziegenspeck-Weg 10, 86161 Augsburg, German \\ ${ }^{\mathrm{d}}$ Institute of Animal Husbandry and Animal Breeding, University of Hohenheim, Garbenstr. 17, 70593 Stuttgart, Germany \\ eInstitute of Medical Biochemistry, Department of Biomedical Sciences/Biochemistry, University of Veterinary Medicine, Veter- \\ inär-Platz 1, 1210 Vienna, Austri
}

corresponding author: Riccarda Wolter: Riccarda.Wolter@gmx.de

'The original publication is available at http://dx.doi.org/10.1016/j.physbeh.2014.05.025, June 2014,

Physiology \& Behavior

\section{Abstract}

The maintenance and development of conservation areas by grazing of large herbivores, such as Przewalski's horses is common practice. Several nature conservation areas house male bachelor groups of this species. When males are needed for breeding they are removed from the groups, often without considering group compositions and individual social positions. However, alpha animals are needed for ensuring group stability and decision making in potentially dangerous situations in several species. To investigate the role of the alpha male in a bachelor group, we observed the behaviour of five Przewalski's horse males during the enlargement of their enclosure. We analyzed the group's social structure and movement orders, as well as the animals' connectedness, activity budgets, and whether they moved with preferred group members and how factors such as social rank influenced the horses' behaviour. We also investigated the excretion of glucocorticoid metabolites (GCM) via faeces of the horses while exploring a new area as a parameter of glucocorticoid production. Our results show that the alpha male is important for a bachelor group in changing environmental conditions. The alpha male had the highest level of connectedness within the group. When exploring the new environment, its position in the group changed from previously being the last to being the first. Furthermore the whole group behaviour changed when exploring the new area. The stallions showed reduced resting behavior, increased feeding and did not stay close to each other. We found that the excretion of glucocorticoid metabolites of most horses rose only marginally during the first days on the new area while only the alpha male showed a significant increased amount of glucocorticoid production during the first day of the enclosure enlargement.

\section{Highlights}

- The alpha male appears to have an outstanding position in the group.

- The alpha male had the highest value of connectedness in the group.

- The alpha male had a higher stress hormone level as his group members.

\section{Keywords:}

alpha male, horse, Equus ferus przewalskii, bachelor

group, group structure

\section{Introduction}

The maintenance and development of conservation areas by grazing of large herbivores, such as horses, red deer, cattle or others is frequently practiced [1,2]. Aside of the grazing, these so called semi-reserves offer space for keeping species with space requirements that are difficult to meet in limited zoo housing, such as the Przewalski's horse (Equus ferus przewalskii) [3]. Especially Przewalski's horse males need lots of space for avoiding conflict with other stallions as they tend to show more aggressive behavior than domestic horses $[4,5,6,7]$. Their aggression level is particularly high when they are kept in small enclosures, which is one of the most common management problems in several species (horses $[8,9]$, 
chimpanzee [10], hens [11]). Other factors which may affect the aggression level of Przewalski stallions are group size, age and the presence of other equids in close vicinity $[6,22]$.

However, the management of male horses in bachelor groups is very important [3] for providing breeding stallions for species conservation programs, such as the European endangered species programme (EEP) [6]. The training of agonistic behavior and development of physical stamina in bachelor groups have been shown to be useful for adequate social development and for the males future reproductive success in many species (canids [12], squirrel monkeys [13], rats [14]) for example, when obtaining and maintaining a future harem in horses $[15,16,17,18]$. Activities such as playing, fighting and mounting were assumed to improve the colt's social skills allowing appropriate interaction when paired with mares [19].

Debate remains about the importance of a stable social organization of managed groups. When males are needed for breeding they are often removed from the groups without considering group compositions and individual social positions [20]. Some authors propose to remove the alpha male and move him to a mare group, as, in unmanaged horse groups, the most dominant male is most likely to become a harem stallion [21]. It has been argued that replacements in bachelor groups are in line with frequent group changes of unstable bachelor groups in the wild [22]. However, in several species alpha animals are needed for reducing the aggression level within the group, for ensuring group stability, for group leading, and for decision making in potentially dangerous situations (primates $[23,24,25,26,27,28]$, hyenas $[29,30]$, deer [31] oryx [32], horse [33]).

Before being extinct in the wild, Przewalski's horses are believed to have formed non-territorial harem bands and bachelor groups similar to feral horses [34]. Range establishment and area, as well as habitat use are discussed in Przewalski's horses. Re-introduced Przewalski's horse groups were reported to remain in separated home ranges, i.e. the area through which groups trek regularly, in search for food, water, minerals and shelter. The size of a group's home range was dependent on the season. Scientists expect home ranges of Przewalski's horse groups to overlap when the number of groups in a habitat increases $[35,36]$.

Studies in feral horses indicate that the social organization and the behavior of equids have remained relatively unaffected by domestication $[37,33,38]$. Bachelor groups include young males which live separate from the natal band and older males who do not hold an own harem [33,18,39]. Usually, small male groups show linear hierarchies [40,34,41]. In breeding groups, movement initiation correlates with social rank, so that dominants are usually followed by subordinates (African Buffalo [42], cattle [43,44], pigeons [45], hyenas [46], feral dogs [47], horses:[37,48]). However, in bachelor groups, the alpha male usually is the last animal in the line, like harem stallions which herd their mares from behind [33,3]. Herding is used to maintain group cohesion when other groups approach or some of the group members separate from the group [6]. Feral dogs [47] and primates [49,28] prefer to move with particular group members, which is not the case for feral horse harems. It remains to be investigated, whether Przewalski's horse males align with certain animals when moving.

The social rank is considered to affect the animal's stress level. In some species, high-ranking males show higher stress hormone levels (glucocorticoids) than lower-ranking males (apes [50], wolves [51,52]). In a natural population of savannah baboons [50] and in wolves [51], the highest-ranking male even had the highest glucocorticoid concentration. In contrast, higher ranking red deer had lower glucocorticoid levels than lower ranking ones [53]. A recent study suggests that stress levels in female domestic horses are independent from rank (study in press). The finding correlates with the suggestion of environmental changes having a clear impact on the stress level of individual animals [54], as reported for dogs $[55,56)$ and mice [57].

In this study, we analyzed the behavior and glucocorticoid level of five semi-wild Przewalski's horse bachelors when their enclosure was enlarged. We analysed the horses' social ranks by applying an Average Dominance Index (ADI) because of its reliability and computational simplicity [58]. We observed the activity budgets of the individual horses and furthermore, we recorded the movement orders, and the distances between the animals by drawing spatial distribution graphs. Moreover, we analyzed the group structure and the connectedness of the horses in affiliative interactions.

The study addresses the following questions: (1) What is the group structure and how are animals connected in the bachelor group? (2) Does the horses behaviour change while they are exploring a new, unknown area? (a) Does then movement order change? (b) Do males preferentially move with certain group members? (c) Do they align with the preferred animals when exploring the enlarged enclosure? (d) Do males show an enhanced glucocorticoid production while exploring a new area and are there any differences between group members?

\section{Materials and Methods}

\subsection{Animals}

We investigated a group of five Przewalski's horse males (Equus ferus przewalskii) living in the Stadtwald Augsburg, Germany, which is part of a large municipal forest. The horses' ages ranged between 1.5 and 6 years with a median of 2.6 years. All horses were individually identified by their brands and colouration (Table 1). Their social history was comparable, as they were all born into small harem groups in zoo housing. They were separated from their natal group when they were between 1 and 2 years old and integrated into the bachelor group at the Stadtwald Augsburg. The horses fed on the natural vegetation in the area, additional food was not provided. The housing area consisted of a 15 ha pine forest, which was enlarged by 15 ha of heathland at October 22nd 2012. Both areas were separated by a fence with two gates.

\subsection{Data sampling}

For social rank evaluations behavioural data was collected by continuous recording for 15 hours ad libitum [59] in September 2012. Moreover, at the pine forest in September 2012 (18th - 21st) and after entering the new area (the heathland) in October 2012 (23rd - 26th) the animals activity budget, the movement order in the group, the movement directions, and the distances between the animals were documented, both for

Table 1

Individual horse data.

\begin{tabular}{llllll}
\hline $\begin{array}{l}\text { Studbook } \\
\text { no. }\end{array}$ & Name & Born & $\begin{array}{l}\text { Living in } \\
\text { Augsburg since }\end{array}$ & ADI & $\begin{array}{l}\text { Social } \\
\text { rank }\end{array}$ \\
\hline 4839 & Marlon & 20.07 .2006 & $06-2007$ & 0.950 & 1 \\
5648 & Solongo & 07.06 .2010 & $09-2011$ & 0.516 & 2 \\
5665 & Xaran & 05.07 .2010 & $09-2011$ & 0.467 & 3 \\
5732 & Vinter & 13.01 .2011 & $06-2012$ & 0.243 & 4 \\
5639 & Kalmoek & 25.05 .2010 & $01-2012$ & 0.083 & 5 \\
\hline
\end{tabular}


16 hours by scan sampling [59] every five minutes. These observations were distributed evenly over 8 daylight hours and were spread over 4 consecutive days.

During the enlargement day at October 22nd, the activity budget, the movement order and direction, as well as the distances between the animals were noted by scan sampling every minute for three hours, from the time point when the horses passed the gates. During all observation days in October we collected faecal samples of all horses for measuring glucocorticoid metabolites. The observer stood about $20 \mathrm{~m}$ away from the animals, depending on their spatial distribution. Due to the fact that the horses are accustomed to people, their behaviour was not influenced by the observer's presence.

\subsection{Social rank}

We counted agonistic behaviours of the group members, such as threats to bite or to kick, bites, kicks, chases, retreats and approaches in agonistic contexts $[18,60]$. The social rank of each horse was calculated with the average dominance index (ADI) from their agonistic encounters (Table 1) as follows. The dominance index per pair of individuals, $\mathrm{w}$ ij is the number of times an individual won against a certain opponent divided by the total number of agonistic encounters between the pair, thus $\mathrm{w} i \mathrm{ij}=\mathrm{x}$ ij / ( $\mathrm{x} \mathrm{ij}+\mathrm{x}$ ji). Wins were counted for the initiator of an encounter when an approached or challenged animal retreated for one step or more. If two individuals were not involved in an encounter with each other, this pair was excluded from the analysis. The average dominance index of an individual is the average of all its dominance indices with all its interaction partners, thus $1 / \mathrm{N} \Sigma \mathrm{j}$ wij. The ADI ranges between 0 and 1 , a higher value indicates a higher dominance rank in the group [58] (Table 1).

The reaction of the receiver, not the type of agonistic behaviour, is decisive for counting wins and losses. For example, an animal may respond by retreating whether it is being kicked or approached. In both cases the receiver loses and the initiator wins. This method enables all agonistic behaviour types to be used, irrespective of their frequency, and provides the largest possible sample size for the dominance calculation [58]. We have chosen the ADI for its reliability and computational simplicity. Studies show that the ADI can deal with missing data between pairs of animals and still provides more reliable results then comparable dominance assessment methods [58].

\subsection{Activity budget}

1. The activity of the animals was calculated from the following activity patterns [61]:

2. Resting (standing approximately motionless, with relaxed facial muscles, ears turned sideways and dropped eyelids; or in a lying position)

3. Standing awake (eyes are wide opened and ears are turned forward, horse is intent)

4. Feeding (walking in search for food and ingestive behaviour)

5. Locomotion (locomotory movements to or from an area)

6. Other (all other activity pattern as e.g. agonistic behaviour, affiliative behaviour, drinking, self-grooming)

For the data analysis, the time budget for all observation periods per animal was calculated to analyze if the horses differed from each other in their activity. Furthermore, the activity budget for the whole group was calculated for each of the three sampling periods before, during and after the enlargement. We calculated the averages of the percentage of activity pattern frequencies for all individuals (Figure 2). As the number of scans differed between the three observation periods (before and after enlargement the scan was taken every 5 minutes, during the enlargement period every minute), we tested whether different observation frequencies effected the results, but found no difference between taking every scan and only every fifth scan of the enlargement periods for the analysis. Therefore, analyses were run with the largest possible sample size (before and after enlargement: every 5 minutes, during the enlargement period every minute).

\subsection{Nearest neighbours, connectedness and group structure}

For analyzing whether the animals preferentially move with certain group members and in a particular distance to their group members each horse's nearest neighbour and the distances to the other animals were recorded at each data sampling. We measured the distance between the head of a particular horse (A) to any body part of a second horse (B) and distinguished between 4 distance categories (Figure 3):

\section{Distance from horse's head to the next horse $<0.5 \mathrm{~m}$}

2. Distance from horse's head to the next horse $=0.5-2 \mathrm{~m}$

3. Distance from horse's head to the next horse $=2-5 \mathrm{~m}$

4. Distance from horse's head to the next horse $=5-10$

To analyze the group structure and each horse's connectedness within the group, we applied network analysis [62]. We measured the connectedness among group members and analyzed the connectedness index for each individual by dividing the number of affiliative interactions of each individual through the total number of affiliative interactions that all animals exchanged among each other.

To analyse the group structure, we investigated whether horses are organized in small-world networks in which all group members interact directly and regularly with each other [63]. Smallworld networks can be measured by analysing a group's clustering coefficient and the average path length from the agonistic and affiliative interactions among group members. The clustering coefficient gives the proportion of group mates that interact with each other, which ranges from 1 for agonistic and affiliative interactions with all animals to 0 for no interactions. The average path length gives a value for whether animals pass on their information directly to each other, with the value 1 for direct information transfer and greater than 1 when information is passed via other animals to reach animals not directly connected to the information provider. In small-world networks the clustering coefficient and the average path length of a group approach the value 1 [63].

\subsection{Movement order}

For analyzing the movement order, we drew spatial distribution graphs of the animals and the direction of movement for each horse at every data sampling.

A movement was recorded when one or more animals moved $\geq 3 \mathrm{~m}$ away from their group members' previous position towards unoccupied space. The animals may either have moved a) from the periphery of the group, b) from the centre of the group, passed other group members and then moved into "unoccupied space", or, c) if the group was scattered, they moved towards unoccupied space within the groups range. A movement could either be accomplished in a single continuous bout that was observed for $\leq 10$ s, or in multiple bouts, with in-between stops of $\leq$ $2 \mathrm{~s}$, that were observed for $\leq 30$ s.

The movement order was recorded:

I. when at least 2 animals moved into the same direction when distribution graphs were drawn, 
II. when the animals moved into the same direction for approximately $50 \%$ of the distance or more and,

III. when the animals moved together at an angle of approximately $15^{\circ}$ or less to the movement direction.

Movements of stallions towards each other for the exchange of social behaviours were not counted.

From the distribution graphs we calculated the percentages of positions during movements for each particular horse (Figure 4 and Figure 5). The data does not allow for distinguishing leadership for the animals as we did not document movement initiations. Generally, movements in Przewalski's horses can be initiated by departing front animals or by herding from behind [64].

\subsection{Faecal cortisol metabolites}

Faecal samples of all horses were collected during the enlargement day and the following observation days in October 2012.

We picked up the samples with unused one-way gloves, stored them in glasses and kept them on ice until freezing. The time until freezing did not take longer than 3 hours. Faecal samples were processed with the method described in Flauger et al. [65]. We extracted cortisol metabolites from the horse faeces as described for faecal GCM extraction in ruminants [66]. In brief, $0.5 \mathrm{~g}$ faeces of an individual sample plus $1 \mathrm{ml}$ water and $4 \mathrm{ml}$ methanol were vortexed for 30 minutes. The methanolic suspension was centrifuged, a small part of the supernatant diluted in assay buffer and directly analysed by an enzyme immunoassay directed against 11-oxoaetiocholanolone-17-CMO coupled to bovine serum albumin. Interassay coefficients of variance for the assay were $13.3 \%$ and $15.7 \%(n=9)$. Values represent percentage variance for high and low quality controls. The enzyme immunoassay was validated for equine faecal glucocorticoid metabolites with an ACTH Challenge Test [65].

Horses excrete GCMs in faeces with a delay of about 24 hours compared to plasma $[66,67]$. Therefore GCMs values were compared to the observations that were made 24 hours before (Figure 6). For example, the values of the GCMs that were assigned to the enlargement day were extracted from the faecal samples that were defecated the day after the enlargement day and the values assigned to the period before the enlargement were extracted from the faecal samples defecated in the morning of the enlargement day.

\subsection{Data analysis}

For statistical analysis we used the R-Project statistical environment ( $\mathrm{R}$ Development Core Team 2011). To compare datasets with low sample sizes we used non-parametric tests. Friedman-exact tests were applied to compare dependent datasets. For the analysis of contingency tables we used Fisher's-exact tests. Correlations were calculated with the Kendall-tau test. We used chi-square exact tests for likelihood equations in metric datasets. An ANOVA was used for comparing the five horses in their deviations of cortisol metabolite excretions between observations. All tests were two-tailed and the significance level was set at 0.05.

\section{RESULTS}

\subsection{Social rank}

The social organization came close to a linear hierarchy (Table 1), with the oldest male Marlon in the top position. Both stallions that came to Augsburg after Marlon had arrived, in 2011, ranked at the positions 2 and 3 and the two males that came to Augsburg last, in 2012, filled the rank 4 and 5. When comparing the interactions of pairs of animals, only the alpha male was dominant over all others. In one case a lower ranking horse dominated a group mate with a higher dominance index (Figure 1). Between the two horses Vinter and Kalmoek no interactions were observed. Kalmoek was placed at the last position, as is ADI value was lower than the ADI of Vinter. The lower ADI was due to the fact that Kalmoek had to retreat from the horses in position 1 and 3 more often than Vinter.

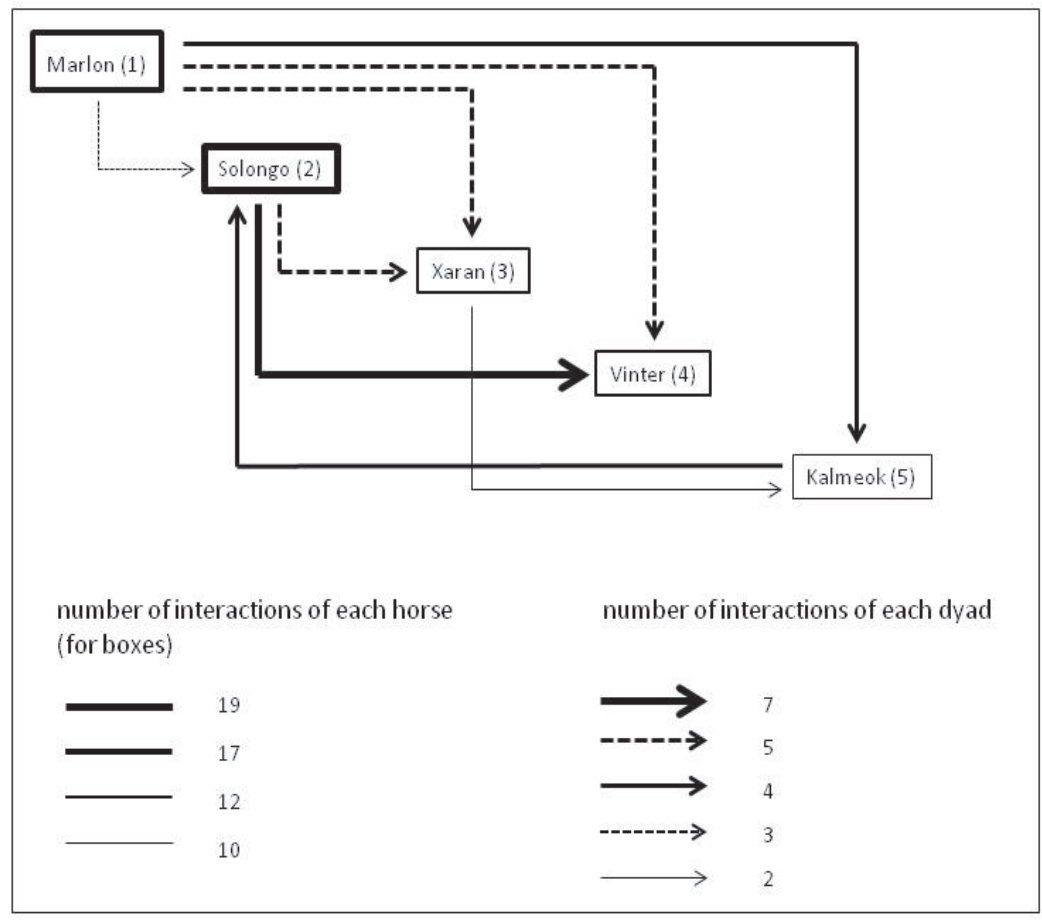

Figure 1. Agonistic sociogramm of the males. The direction of the arrows indicates which horses were dominant over the others. The different diameters of the boxes indicate the interaction proportions of each horse and the different diameters of the arrows indicate the interaction proportions of each dyad. 


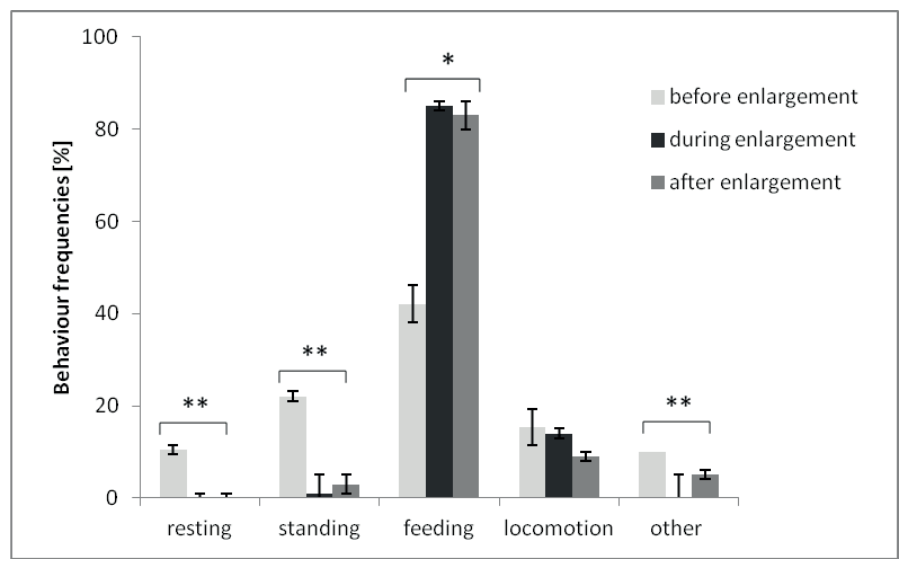

Figure 2. Percentage of behaviours displayed during the three observation periods. Homochromatic bars add to $100 \%$. The bars depict the mean of the particular behaviour data from the 5 stallions and the whiskers show the standard deviation. Significant differences are given with ${ }^{\star}$ for $\mathrm{P}<0.05$, with ${ }^{\star *}$ for $\mathrm{P}<0.01$ and with ${ }^{\star * *}$ for $\mathrm{P}<0.001$.

\subsection{Activity budget}

All activity patterns were shown from all animals during our data sampling, but with different frequencies. Before the enclosure was enlarged, the observed animals spent $42 \%$ of their time feeding, $22 \%$ standing awake, $11 \%$ resting, $15 \%$ in locomotion, and $10 \%$ for other behaviors (Figure 2). At the day of enclosure enlargement and during the observations of the following days, the males showed reduced resting behavior (Friedman-exact test: $\mathrm{N}=5, \chi 22=9.5, \mathrm{P}=0.009$ ) and reduced standing (Friedman-exact test: $\mathrm{N}=5, \chi 22=9.58, \mathrm{P}=0.008$ ). In contrast, the proportion of feeding behavior increased during the enclosure enlargement (Friedman-exact test: $\mathrm{N}=5, \chi 22=8.44, \mathrm{P}=0.015$ ). While the proportion of locomotion didn't change, other behavior pattern were only shown before and after the enclosure enlargement, not during the enlargement period (Friedman-exact test: $\mathrm{N}=5, \chi_{22}$ $=10, \mathrm{P}=0.007)$.

Comparing the activity budgets off all horses during the day of enclosure enlargement, we found that all horses showed almost the same proportions off all behavioural categories. Only Marlon, the alpha male, showed more locomotion and standing awake than other group members, but the difference between the group members was not significant (Friedman-exact test: "locomotion": $\mathrm{N}=5, \chi 22=7.12, \mathrm{P}=0.125$; "standing awake": $\mathrm{N}=5$, $\left.\chi^{22}=5.21, \mathrm{P}=0.579\right)$.

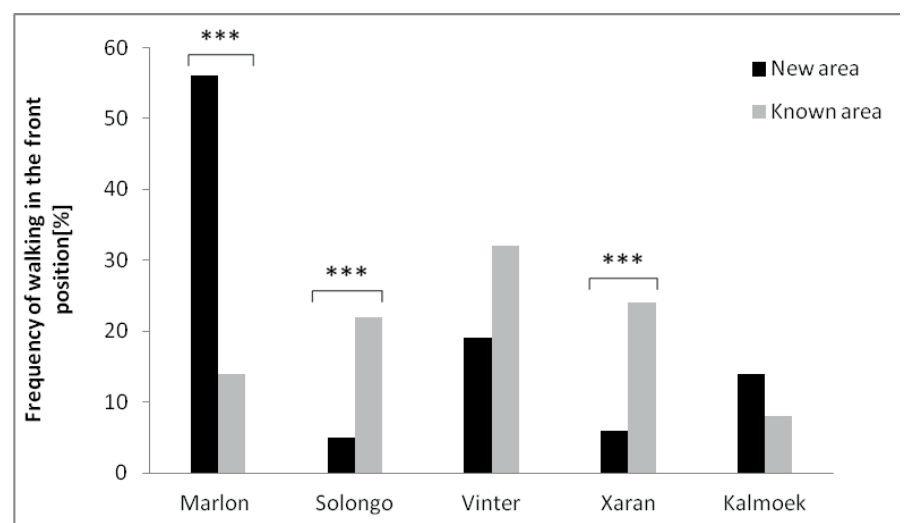

Figure 4. Percentage of walking in the front position for each male. The two graphs show the percentages of being in the front position at the old, known area and during the exploration of the new area. Significant differences are given with ${ }^{*}$ for $\mathrm{P}<0.05,{ }^{* *}$ for $\mathrm{P}<0.01$ and ${ }^{* * *}$ for $\mathrm{P}<$ 0.001 .

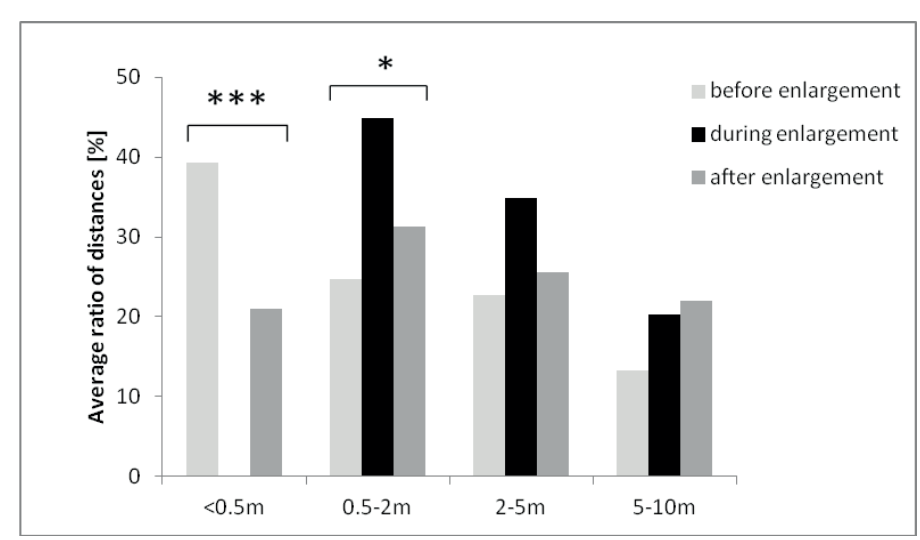

Figure 3. Percentage of distance categories during the three observation periods. The columns show the different distance categories during each observation. During the enlargement horses were never $<0.5 \mathrm{~m}$ apart from each other. Significant differences are given with ${ }^{*}$ for $\mathrm{P}<$ 0.05 , with ${ }^{* *}$ for $\mathrm{P}<0.01$ and with ${ }^{* *}$ for $\mathrm{P}<0.001$.

\subsection{Nearest neighbours, connectedness and group structure}

All distance categories were found between all pairs during the observations before and after the enlargement. During the enclosure enlargement the smallest distance category of $<0.5$ meters wasn't shown by the stallions (Figure 3), in contrast to the preceding and following days $\left(\mathrm{Chi}^{2}\right.$-test: $\left.\chi^{2} 2=38.1, \mathrm{P}<0.001\right)$. Instead, the distance category of $0.5-2$ meters occurred more often during the enclosure enlargement period $\left(\mathrm{Chi}^{2}\right.$-test: $\chi^{2} 2=$ 6.059, $\mathrm{P}=0.048)$.

All horses interacted with all group members directly. The clustering coefficient of the group and the average path length for information transfer was $1(\mathrm{~N}=5)$, which implies, that information was transferred directly (clustering coefficient) and not via other group members (average path length). Therefore, the bachelor group can be considered to be organized in a smallworld network.

The individuals differed in their degree of affiliative behaviour exchange. The connectedness between group mates, demonstrated by the degree of affiliative behaviour exchange, gradually decreased from the alpha male Marlon, with the highest connectedness to Xaran with the lowest connectedness (Ngrooming $=31$, Nanimals $=5$, conn. Index: "Marlon" $=0.77$, "Solongo"= 0.52 , "Vinter" $=0.42$, "Kalmeok" $=0.23$ "Xaran"=0.06). The animals' degree of connectedness did no correlate with their social rank in the group (Kendall-tau test: $\tau=0.599, \mathrm{P}=0.221$ ).

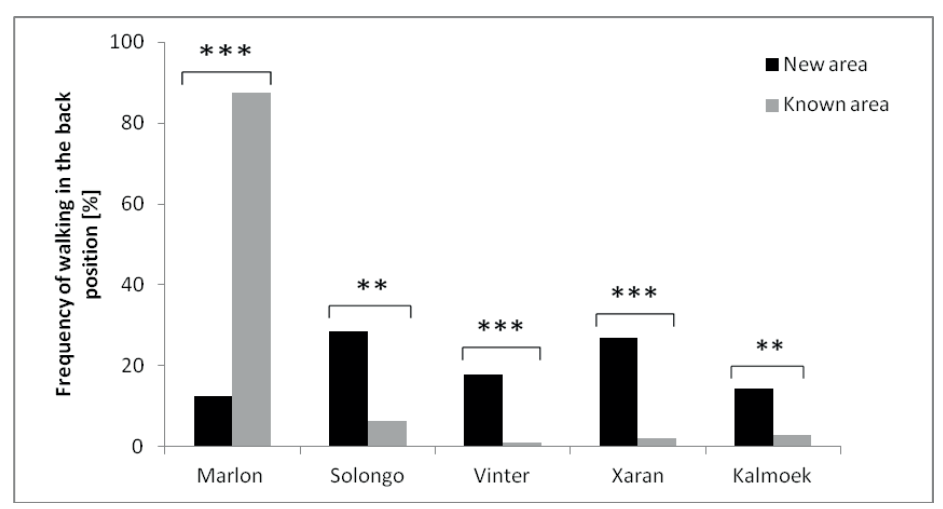

Figure 5. Percentage of walking in the back position for each male. The two graphs show the percentages of being in the last position at the old, known area and during the exploration of the new area. Significant differences are given with ${ }^{\star}$ for $\mathrm{P}<0.05,{ }^{\star *}$ for $\mathrm{P}<0.01$ and ${ }^{\star * *}$ for $\mathrm{P}<$ 0.001 . 


\subsection{Movement order}

Moving in front position was shown by all five horses. But the proportion of walking in front of the group changed for each horse between September, on the well-known area, and October, on the new area (Figure 4) $\left(\mathrm{Chi}^{2}\right.$-test: „known area“: $\chi^{2} 2=$ 17.200, $\mathrm{P}=0.002$; "new area": $\left.\chi^{2} 2=87.700, \mathrm{P}<0.001\right)$. The alphamale Marlon showed a significant higher frequency of walking in front of the group in the new area (Fisher-exact test: $\mathrm{P}<0.001$ ), whereas Solongo and Xaran passed significantly less time in the first position at the new habitat (Fisher-exact test: "Solongo": P < 0.001, "Xaran": $\mathrm{P}<0.001)$.

We compared the percentage of each animal of walking in the different positions in September and found an unbalanced distribution for all horses, as all males preferred some positions and avoided walking in others. Vinter walked mainly in the first position (Chi ${ }^{2}$-test: $\left.\chi^{2} 4=29.3, \mathrm{P}<0.001\right)$ and Solongo in the second position ( $\mathrm{Chi}^{2}$-test: $\left.\chi^{2} 4=12.65, \mathrm{P}=0.013\right)$. Xaran showed the most balanced distribution with the highest value in the fourth position ( $\mathrm{Chi}^{2}$-test: $\left.\chi^{2} 4=10.7, \mathrm{P}=0.03\right)$, as well as Kalmoek, that preferred also the fourth position (Chi ${ }^{2}$-test: $\chi^{2} 4=25.2, \mathrm{P}<$ $0.001)$. The alpha male spent most time in the last position walking behind all other stallions $\left(\mathrm{Chi}^{2}\right.$-test: $\left.\chi^{2} 4=128.7, \mathrm{P}<0.001\right)$. The favoured walking position did not correlate with the social rank of the animals (Kendall-tau test: $\tau=-0.316, P=0.613$ ).

As the number of walking in the front position between the different areas changed for some individuals, we evaluated how often the individuals were in the back of the group (Figure 5). Similar to the results of walking in the front position, we found that the frequency of the alpha male changed significantly between test situations, as he had a higher frequency of walking in the back of the group on the known area (Fisher-exact test: "Marlon": P < 0.001). All other stallions showed a higher rate of walking in the back of the group on the new area (Fisher-exact test: "Solongo": $\mathrm{P}<0.01$, "Vinter": $\mathrm{P}<0.001$, "Xaran": $\mathrm{P}<0.001$, "Kalmoek": P < 0.01).

\subsection{Faecel cortisol metabolites}

The glucocorticoid metabolites were analyzed before the horses entered the new area and on the first three days at the new area. We compared the values of all animals for the four consecutive days and found that only two horses showed significant deviations from the cortisol metabolite values of their group mates (Chi ${ }^{2}$-test: „Marlon“: $\mathrm{N}=4, \chi^{2} 3=11.529, \mathrm{P}=0.009$; „Kalmoek“: $\left.\mathrm{N}=4, \chi^{2} 3=10.227, \mathrm{P}=0.017\right)$. The alpha male had the lowest GCM values before the enclosure enlargement (Figure 6), but the value did not differ significantly from the GCM values of the other animals. He showed a higher faecal cortisol metabolite increase than any other group member from the day before to the day of the enlargement (ANOVA: F1,5 $=9.522, \mathrm{P}=0.05$ ) and stronger decrease from the day of the enlargement to the first day after the enclosure was enlarged (ANOVA: F1,5 = 33.23, P = 0.01 ). The GCM's of all the other group members increased only marginally and not significantly.

\section{DISCUSSION}

In the present study, the alpha male took the initiative during the enclosure enlargement and changed his walking position from the last to the front position. We found that the alpha male had a higher increase of cortisol metabolites and a higher ratio of locomotion and standing awake than any other group member during the enlargement day. Additionally, the alpha animal had the highest level of social connectedness within the group, which supports the thesis of his great importance for the group [32].

\subsection{The hierarchy was nearly linear}

The hierarchy in the observed bachelor group was linear when the ADI values were taken into account. When comparing the outcome of interactions for the possible dyads, we found that one male with a lower ADI value dominated a stallion with a higher ADI value. This supports other studies which suggest linear hierarchies to be common in bachelor groups of horses [68,37,3,21]. Especially for small groups, with up to 9 horses, strong linear hierarchies were reported [69]. The inconsistency in the hierarchy of the present group may be caused by the fact that 4 of the 5 stallions were immature and at almost similar age. Consistent with other studies $[40,37,38]$, we found the oldest animal to be at the top position of the hierarchy.

\subsection{Feeding behaviour increased and resting behaviour dimin- ished during enlargement}

The time the observed Przewalski's horses spent feeding before their enclosure was enlarged is in line with the report of [61]. However, when the enclosure was enlarged by an area with - compared to the forest enclosure - rich vegetation the horses' feeding duration increased to its double. The time the horses spent standing awake before the enclosure was enlarged is comparable to the study of Boyd et al. [61], but we observed less resting behaviour, including standing resting and laying down laterally at their sides and sternally at their chests. The difference of observed resting behavior may be a seasonal deviation as Boyd et al. [61] observed Przewalski's horses during the summer. During the enclosure enlargement and in the following days resting and standing awake were hardly ever shown as the horses were busy with feeding. Other influencing factors as the weather, the harassment of blood sucking insects and the body condition of the horses seemed not to effect their behaviour, as all of these factors stayed almost the same during the study. Only the mean temperature was lower in October than in September. The most influencing fact that affected the behaviour of the horses appeared to be the diet in the different biotopes, as there was a high offer of old grass on the enlargement area. This aspect will be analyzed and presented in detail in a follow up publication.

In the present study the horses' level of locomotion is comparable to the study of Popolow [70], in which Przewalski's horses spent $13 \%$ of their time with locomotion. All together, the horses were more active during the enlargement period, but the level of locomotion didn't change between observation situations, as movements that were done during grazing were assigned to the feeding behaviour. This fits our observations that the horses did not travel longer distances on the new area.

Other behaviours as drinking, self-grooming, mutual grooming or playing were shown as well before and after the enlargement, but not during the first inspection of the new area.

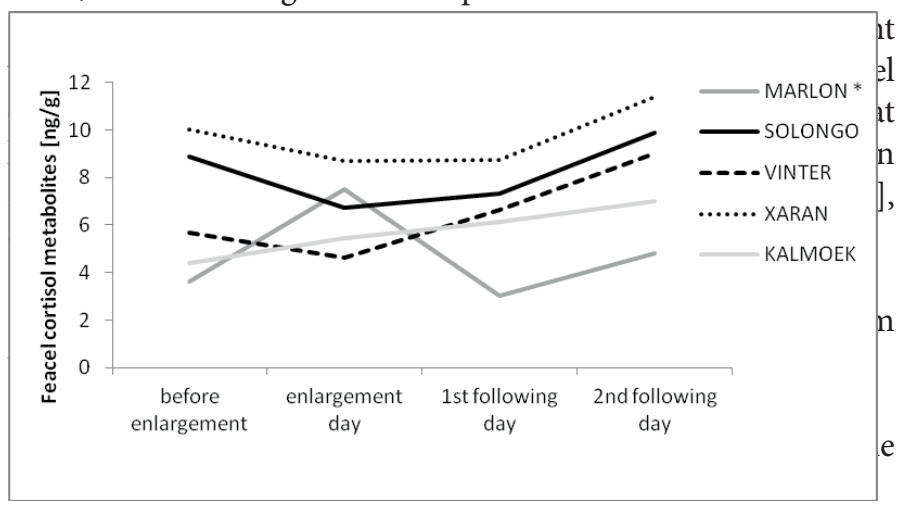

Figure 6. Faecal cortisol metabolites of the stallions. The $\mathrm{x}$-axis lists the different days on which faecal samples were collected. The star indicates the alpha male. 
group and herds the group from behind [34]. This typical behaviour was shown before the enlargement quite often, as the alpha male spent most of the time walking in the back of the group. When the enclosure was enlarged, the alpha stallion walked in the front position most often. The other group members took over the front position almost equally often but seldom.

In line with other studies in horses [64] and other species $[72,73,74]$ we found a variable distribution of taking the front position when moving and a variable movement order.

\subsection{Nearest neighbor frequencies changed on the new area}

In theoretical approaches, one of the main characteristics of the social behavior of grazing animals is how they distribute themselves across the landscape [75], as the frequency of spatial closeness may serve as quantitative indicator for associations between group members [76]. Distances between grazing animals are also affected by the risk of predation, as most sheep will flock together in response to a fearful stimulus [77]. Within groups of sheep, some individuals tend to stay closer to their neighbours than others [78], which could be due to differences in the fear of predators and/or differences in social motivation.

Christensen et al. [7] found that Przewalski's horses tend to show a closer contact to each other as domestic horses, as the study group did not spread out on large pasture available, but grouped up tightly. Moreover, the horses maintained a significantly shorter distance to their 1st and 2nd direct neighbours, than did domestic stallions. Other authors report about environmental influences on group spacing behaviour in feral ponies, for example the temperature [37] and fly harassment [79]. These influences should not have been affecting our observed horse group. The mean temperature in September 2012 was $13^{\circ} \mathrm{C}$, whether in October 2012 the temperature had a mean value of $7,84^{\circ} \mathrm{C}$. As it is reported, that horses tend to stay closer to each other during cold temperatures, our findings were opposite to this. For that reason the area seems to have had a greater impact to the distribution than the temperature had. The number of insect attacks was very low as well during September as in October.

In our study we found that during the enclosure enlargement, the Przewalski's horses did not stay in a distance smaller than 0.5 meters to each other, but spread more widely over the new area as on the older enclosure. This may have been caused by the fact that they did not show resting behaviour during the enlargement for which horses usually stay closer to each other [80]. Moreover, the spatial distribution of the group may have been caused by a vegetation change [81] from pine forest to grassland. The new area seems not to have frightened the horses, as there is no indication that they were staying closer to each other.

All horses interacted directly. The interactions were affiliative as well as agonistic and most pairs showed both interaction ways. For all pairs we found at least one kind of both alternative interaction possibilities. The horses in the present study can be considered to be organized in small world networks $[63,62]$ in which most members interact with each other directly with similar frequencies. This group structure provides the basis for equal information transfer. But the number of affiliative interactions with other group members differed for the individuals. The alpha male exchanged affiliative behavior with all group mates, whereas one male, Xaran, interacted affiliatively with only one other individual and showed a very small number of grooming events so that he had the smallest connectedness index.

\subsection{The animals were not stressed by their new environment}

Stress is a general term used to describe environmental factors solicitating adaptation mechanisms and the response to these challenges [82]. An organism can show two different responses to stress. Firstly, the HHN-System (hypophysis-hypothalamus adrenal cortex system) can be mobilized, which leads to an increased biosynthesis and the release of cortisol from the adrenal cortex. Secondly, the SAM-system (sympatho-adrenal medullar system) may release adrenalin and noradrenalin [83]. In the present study the catecholamines, adrenalin and noradrenalin, were not analyzed. We focused on the expression of the cortisol metabolites.

In our study the animals responded to the challenges of their environment with only a marginally increase of glucocorticoid metabolites (GCMs).

It remains debatable, whether the animals of the present study experienced a positive activation of the stress response systems (i.e. eustress) or environmental stimuli of aversive nature (i.e. distress) [84]. Especially uncontrollable and / or unpredictable situations are likely to cause distress, which is expressed in physiological responses, such as depressions of immune functions, and changes in glucocorticoid as well as catecholamine secretion [85].

For analyzing, whether horses perceive environment enlargements as an uncontrollable or unpredictable situation catecholamin and immune system reactions should be controlled in a corresponding, follow up study.

However, on the enlargement day, the alpha male showed the highest increase of excreted GCMs. A reason for that could have been the change of his spatial position in the group. He was in the front position during most group movements and therefore behaved in an unusual way, as the alpha stallion normally walks behind his group $[33,3]$.

Before the enlargement period, the alpha male had the lowest GCM value. This is in contrast to other studies which report that the highest ranking males exhibit higher stress hormone levels [50] but supports the thesis of environmental changes having a clear impact on the stress level of individual animals [54].

The reader should keep in mind, that it is a case study with some limitations because of the small sample size. Nevertheless, most of the results are very well comparable to many other studies $[3,21,38,61,64,70]$, but for a generalization of the results, the study should be expanded to a larger population.

\section{CONCLUSION}

We found that the alpha male appears to have an outstanding position in the group. During the enlargement period, especially the alpha stallion showed a higher frequency of walking in the front position and had a higher stress hormone level as his group members. Moreover, he had the highest value of connectedness in the group. In general, the horses didn't seem to be very stressed when they explored the new area, as their cortisol metabolites increased only marginally. A follow up study is needed for evaluating how fast the alpha position will be replaced when the alpha animal is removed from the group. Moreover, it should be investigated, if and to what degree younger stallions learn from the alpha male and how important he is for the group stability, for reducing the aggression level and for decision making.

\section{Acknowledgements}

We would like to thank the owner of the Przewalski's horses, the Zoo of Augsburg and the Landschaftspflegeverband Stadt Augsburg e.V. for the permission to observe the animals and Knut Krüger for help with the "R"-environment as well as Jürgen Heinze and Birgit Flauger for helpful discussions. 


\section{References}

[1] Bullock JM, Pakeman RJ. Grazing of lowland heath in England: Management methods and their effects on heathland vegetation. Biol Conserv 1996; 79: $1-13$.

[2] Brockway DG, Lewis CE. Influence of deer cattle grazing and timber harvest on plant species diversity in a longleaf pine bluestem ecosystem. Forest Ecol Manag 2003; 175: 49-69.

[3] Tilson RL, Binczik GA, Reindl NJ, Sweeny KA. Buddies and bullies: social structure of a bachelor group of Przewalski horses. Appl Anim Behav Sci 1988; 21: 169-85.

[4] Feh C. Social behaviour and relationships of Przewalski horses in Dutch semireserves. Appl Anim Behav Sci 1988; 21: 71-87.

[5] Van Dierendonck MC, Bandi N, Batdorj D, Dügerlham S, Munkhtsog B. Behavioural observations of reintroduced Takhi or Przewalski horses (Equus ferus przewalskii) in Mongolia. Appl Anim Behav Sci 1996; 50: 95-114.

[6] Kolter L, Zimmermann W. The keeping of Przewalski's horse bachelor groups for the EEP - Stallions living in enclosures and reserves. Z Kölner Zoos 2001; 44: 135-51.

[8] Skiff EM. The effect of enclosure design on social interactions and daily activity patterns of the captive Asiatic wild horse (Equus przewalskii). Master's Thesis; Minnesota: University of Minnesota; 1982.

[7] Christensen JW, Zharkikh T, Ladewig J, Yasinetskaya N. Social behavior in stallion groups (Equus przewalskii and Equus caballus) kept under natural and domestic conditions. Appl Anim Behav Sci 2002; 76: 11-20.

[9] Hogan ES, Houpt KA, Sweeney K. The effect of enclosure size on social interactions and daily activity patterns of the captive asiatic wild horse (Equus przewalskii). Appl Anim Behav Sci 1988; 21: 147-68.

[10] Bloomsmith MA, Laule GE, Alford PL, Thurston RH. Using training to moderate chimpanzee aggression during feeding. Zoo biol 1994; 13: 557-66.

[11] Hughes BO, Wood-Gush DGM. Agonistic behaviour in domestic hens: The influence of housing method and group size. Anim Behav 1977; 25: 1056 162.

[12] Bekoff M. Social Play and Play-Soliciting by Infant Canids. Am Zool 1974; 14: 323-40.

[13] Biben M. Squirrel monkey play fighting: making the case for a cognitive training function for play. In: Bekoff M, Byers JA, editors. Animal Play. Evolutionary, Comparative, and Ecological Perspectives, Cambridge: Cambridge University Press; 1998, pp. 161-82.

[14] Pellis SM, Pellis VC. Play and the development of social engagement: A comparative perspective. In: Marshall PJ, Fox NA, editors. The development of social engagement, Neurobiological perspectives, Oxford: Oxford University Press; 2006, pp. 247-74.

[15] Klingel H. Die soziale Organisation freilebender Equiden. Equus 1980; 2: $128-31$.

[16] Berger J. Wild horses of the great basin. Chicago: University of Chicago Press; 1986.

[17] Berger J. Reproductive fates of dispersers in a harem-dwelling ungulate, wild-horses. In: Chepko-Sude D, Hapin Z, editors. Mammalian Dispersal Patterns: The Effects of Social Structure on Population Genetecis, Chicago: The university of Chicago Press; 1987, pp. 41-54.

[18] McDonnell SM, Haviland JCS. 1995. Agonistic ethogram of the equid bachelor band. Appl Anim Behav Sci 1995; 43: 147-88.

[19] Boyd L, Houpt KA. Activity Patterns. In: Boyd L, Houpt KA, editors. Przewalski's Horse: The history and biology of an endangered species, New York: State University of New York Press; 1994, pp. 195-227.

[20] Krueger K, Flauger B, Farmer K, Hemelrijk CK. Movement initiation in groups of horses. Behav Process; in press.

[21] Zharkikh TL, Andersen L. Behaviour of Bachelor Males of the Przewalski Horse (Equus ferus przewalskii) at the Reserve Askania Nova. Zool Garten 2009; 78: 282-99.

[22] Puschmann W. Zootierhaltung, Tiere in menschlicher Obhut, Säugetiere. 4th ed. Frankfurt: Harri Deutsch Verlag; 2007.
[23] Henzi SP, Lycett JE, Weingrill T. Mate guarding and risk assessment by male mountain baboons during inter-troop encounters. Anim Behav 1998; 55: 1421-8.

[24] Aureli F, de Waal FBM. Natural conflict resolution. Berkley: University of California Press; 2000.

[25] Flack JC, de Waal FBM, Krakauer DC. Social structure, robustness, and policing cost in a cognitively sophisticated species. Am Nat 2005; 165: 126-39.

[26] Flack JC, Girvan M, de Waal FBM, Krakauer DC. Policing stabilizes construction of social niches in primates. Nature 2006; 439: 426-9.

[27] Flack JC, Krakauer DC, de Waal FBM. Robustness mechanisms in primate societies: a perturbation study. P Roy Soc of Lond B Bio 2005; 272: 1091-9.

[28] King AJ, Douglas CMS, Huchard E, Isaac NJB, Cowlishaw G. Dominance and affiliation mediate despotism in a social primate. Curr Biol 2008; 18: 1833-8.

[29] Zabel CJ, Glickman SE, Frank LG, Woodmansee KB, Keppel G. Coalition formation in a colony of prepubertal spotted hyaenas. In: Harcourt AH, de Waal FBM, editors. Coalitions and Alliances in Humans and Other Animals, Oxford: Oxford University Press; 1992, pp. 113-35.

[30] Smith JE, Van Horn RC, Powning KS, Cole AR, Graham KE, Memenis SK, et al. Evolutionary forces favoring intragroup coalitions among spotted hyenas and other animals. Behav Ecol 2010; 21: 284-303.

[31] Jennings DJ, Carlin CM, Gammell MP. A winner effect supports third-party intervention behaviour during fallow deer (Dama dama) fights. Anim Behav 2009; 77: 343-8.

[32] Walther FR. On herding behavior. Appl Anim Behav Sci 1991; 29: 5-13.

[33] Feist JD, McCullough DR. Behavior patterns and communication in feral horses. Z Tierpsychol 1976; 41: 337-71.

[34] Berger J. Organizational systems and dominance in feral horses in the Grand Canyon. Behav Ecol Sociobiol 1977; 2: 131-46.

[35] King SRB. Home range and habitat use of free-ranging Przewalski horses at Hustai National Park, Mongolia. Appl Anim Behav Sci 2002; 78: 103-13.

[36] King SRB, Gurnell J. Habitat use and spatial dynamics of takhi introduced to Hustai National Park, Mongolia. Biol Conserv 2005; 124: 277-90.

[37] Tyler SJ. The behaviour and social organization of the New-Forest-Ponies. Anim Behav Monogr 1972; 5: 85-196.

[38] Waring GH. Horse Behaviour. The Behavioural Traits and Adaptions if Domestic and Wild Horses, including Ponies. New Jersey: Noyes Publications; 1983.

[39] Khalil AM, Kaseda Y. Early experience affects developmental behaviour and timing of harem formation in Misaki horses. Appl Anim Behav Sci 1998; 59: 253-63.

[40] Grzimek B. Rangordungsversuche mit Pferden. Z Tierpsychol 1949; 6: 45564.

[41] Houpt KA, Keiper R. The position of the stallion in the equine dominance hierarchy of feral and domestic ponies. J Anim Sci 1982; 54: 945-50.

[42] Prins HH. Ecology and Behaviour of the African Buffalo: Social Inequality and Decision Making. Dordrecht: Springer Netherland; 1995.

[43] Šárová R, Spinka M, Panamá JLA. Synchronization and leadership in switches between resting and activity in a beef cattle herd--A case study. Appl Anim Behav Sci 2007; 108: 327-31.

[44] Šárová R, Spinka M, Panamá JLA, Simecek P. Graded leadership by dominant animals in a herd of female beef cattle on pasture. Anim Behav 2010; 79: 1037-45.

[45] Nagy M, Akos Z, Biro D, Vicsek T. Hierarchical group dynamics in pigeon flocks. Nature 2010; 464: 890-3.

[46] Holekamp KE, Boydston EE, Smale L. Group travel in social carnivores. Chicago: Chicago University Press; 2000.

[47] Bonanni R, Cafazzo S, Valsecchi P, Natoli E. Effect of affiliative and agonistic relationships on leadership behaviour in free-ranging dogs. Anim Behav 2010; 79: 981-91.

[48] Heitor F, do Mar Oom M, Vicente L. Social relationships in a herd of Sorraia horses Part I. Correlates of social dominance and contexts of aggression. Behav Process 2006; 73: 170-7. 
[49] Byrne RW, Whiten A, Henzi SP. Social relationships of mountain baboons: Leadership and affiliation in a non-female-bonded monkey. Am J Primatol 1990; 20: 313-29.

[50] Gesquiere LR, Learn NH, Simao CM, Onyango PO, Alberts SC, Altman J. Life at the Top: Rank and Stress in Wild Male Baboons. Science 2011; 333: 357-60.

[51] Sands J, Creel S. Social dominance, aggression and faecal glucocorticoid levels in a wild population of wolves, Canis lupus. Anim Behav 2004; 67: 387-96.

[52] Muller MN, Wrangham RW. Dominance, cortisol andstress in wild chimpanzees (Pan troglodytes schweinfurthii). Behav Ecol Sociobiol 2004; 55: $332-40$.

[53] Balfanz F. Quantifizierung der Stressbelastung beim Rothirsch: Auswirkung von Stoffwechselaktivität und sozialen Hierarchien. Deutsche Wildtierstiftung: Abschlussbericht; 2005.

[54] Wiepkema PR, Koolhaas JM. Stress and animal welfare. Anim Welfare 1993; 2: 195-218.

[55] Sigg H, Tobler I. Motor activity of mongrel dogs under three different housing conditions. Z Versuchstierkd 1986; 28: 157-65.

[56] Beerda B, Schilder MB, van Hooff JA, de Vrie HW, Mol JA. Chronic stress in dogs subjected to social and spatial restriction I. Behavioural Responses. Physiol Beha 1999; 66: 233 -42.

[57] Van Loo PLP, Van der Meer E, Kruitwagen CLJJ, Koolhaas JM, Van Zutphen LFM, Baumans V. Long-term effects of husbandry procedures on stressrelated parameters in male mice of two strains. Lab Anim 2004; 38: 169-77.

[58] Hemelrijk CK, Wantia J, Gygax L. The construction of dominance order: comparing performance of five methods using an individual-based model. Behaviour 2005 ; 142: 1043-64.

[59] Martin P, Bateson P. Measuring behaviour - An introductory guide. 2nd. ed. Cambridge: University press; 1986.

[60] McDonnell SM. The Equid Ethogram: A Practical Field Guide to Horse Behavior. Lexington, Kentuky: Eclipse Press; 2003.

[61] Boyd LE, Carbonaro DA, Houpt KA. The 24-hour time budget of Przewalski horses. Appl Anim Behav Sci 1988; 21: 5-17.

[62] Croft DP, James R, Krause J. Exploring animal social networks. Princeton: Princeton University Press; 2008.

[63] Watts DJ, Strogatz SH. Collective dynamics of 'small-world' networks. Nature 1998; 393: 440-2.

[64] Bourjade M, Thierry B, Maumy M, Petit O. Decision-making in Przewalski horses (Equus ferus przewalskii) is driven by the ecological contexts of collective movements. Ethol 2009; 115: 321-30.

[65] Flauger B, Krueger K, Gerhards H, Möstl E. Simplified method to measure glucocorticoid metabolites in faeces of horses. Vet Res Commun 2010; 34: 185-95.

[66] Palme R, Möstl E. Measurement of cortisol metabolites in faeces of sheep as a parameter of cortisol concentration in blood. In: Proceedings, 1stInternational Symposium Physiology and Ethology of Wild and Zoo Animals, Berlin, Germany; 1996, p. 84.
[67] Möstl E, Messmann S, Bagu E, Robia C, Palme R. Measurement of glucocorticoid metabolite concentration in faeces of domestic livestock. J Vet Med A 1999; 46: 621-31.

[68] Feist JD. Behavior of feral horses in the Pryor Mountain Wild Horse Range. Master's Thesis; Michigan: University of Michigan; 1971.

[69] Houpt KA, Law K, Martinisi V. Dominance hierarchies in horses. Appl Anim Ethol 1978; 4: 273-83.

[70] Popolow C. Time budgets of Equus przewalskii at the Bronx Zoo. Unpublished Under- graduate Research Paper. Ithaca, New York: Cornell University; 1984.

[71] Kitchen DM, Cheney DL, Seyfarth RM. Male chacma baboons (Papio hamadryas ursinus) discriminate loud call contests between rivals of different relative ranks. Anim cogn 2005; 8: 1-6.

[72] Lamprecht J. Variable leadership in bar-headed geese (Anser Indicus): an analysis of pair and family departures. Behav 1992; 122: 105-19.

[73] Leca J-B, Gunst N, Thierry B, Petit O. Distributed leadership in semifreeranging white-faced capuchin monkeys. Anim Behav 2003; 66: 1045-52.

[74] Mirabet V, Fréon P, Lett C. Factors affecting information transfer from knowledgeable to naive individuals in groups. Behav Ecol Sociobiol 2008; 63: 159-71.

[75] Sibbald AM, Elstion DA, Smith DJF, Erhard HW. A method for assessing the relative sociability of individuals within groups: an example with grazing sheep. Appl Anim Behav Sci 2005; 91: 57-73.

[76] Wasilewski A. 2003. 'Friendship' in ungulates? - Sociopositive relationships between non-related herd members of the same species. Dissertation; Marburg: Philipps-Universität Marburg; 2003.

[77] Krause J. Differential fitness returns in relation to spatial position in groups. Biol Rev Camp Philos Sco 1994; 69: 187-206.

[78] Lynch JJ, Woodgush DGM, Davies HJ. .Aggression and nearest neighbours in a flock of Scottish Blackface ewes. Biol Behav 1985; 10: 215-25.

[79] Rutberg AT. Horse fly haressment and the social behavior of feral ponies. Ethology 1987; 75: 145-54.

[80] Duncan P, Vigne N. The effects of group size in horses on the rate of attacks by blood-sucking flies. Anim Behav 1979; 17: 623-5.

[81] Dwyer CM, Lawrence AB. Ewe-ewe and ewe-lamb behaviour in a hill and a low land breed of sheep: a study using embryo transfer. Appl Anim Behav Sci 1999; 61: 319-34.

[82] Mormède P, Andanson S, Aupérin B, Beerda B, Guémené D, Malmkvist J, et al. Exploration of the hypothalamic-pituitary-adrenal function as a tool to evaluate animal welfare. Physiol Behav 2007; 92: 317-39.

[83] Henry JP, Stephens PM. Stress, health and the social environment; A sociobiologic approach to medicine. Berlin: Springer-Verlag; 1977.

[84] Buwalda B, Scholte J, de Boer SF, Coppens CM, Koolhaas JM. The acute glucocorticoid stress response does not diffenrentiate between rewarding and aversive social stimuli in rats. Horm Behav 2012; 61: 218-26.

[85] Koolhaas JM, Bartolomucci A, Buwalda B, de Boer SF, Flugge G, Korte SM, Meerlo P, Murison R, Olivier B, Palanza P, Richter-Levin G, Sgoifo A, Steimer T, Stiedl O, van Dijk G, Wohr M, Fuchs E. Stress revisited: a critical evaluation of the stress concept. Neurosci Biobehav Rev 2011; 35: 1291-1301. 











